\title{
Possible predictive role of electrical risk score on transcatheter aortic valve replacement outcomes in older patients: preliminary data
}

This article was published in the following Dove Press journal:

Clinical Interventions in Aging

\author{
Gianfranco Piccirillo' \\ Federica Moscucci' \\ Fabiola Mastropietri \\ Claudia Di lorio' \\ Marco Valerio Mariani' \\ Marcella Fabietti' \\ Gaetana M Stricchiola' \\ Ilaria Parrotta' \\ Gennaro Sardella' \\ Massimo Mancone' \\ Damiano Magri ${ }^{2}$ \\ 'Department of Cardiovascular, \\ Respiratory, Nephrological, \\ Anesthesiologic, and Geriatric \\ Sciences, Policlinico Umberto I, \\ "La Sapienza" University of Rome, \\ Rome, Italy; ${ }^{2}$ Department of Molecular \\ and Clinical Medicine, S. Andrea \\ Hospital, "Sapienza" University of \\ Rome, Rome, Italy
}

Correspondence: Federica Moscucci Dipartimentodi Scienze Cardiovascolari, Respiratorie, Geriatriche,

Anestesiologiche e Nefrologiche,

"Sapienza" University of Rome, Viale del

Policlinico, 00 I85, Rome, Italy

Tel +39 6499701 I8

Email gianfranco.piccirillo@uniromal.it
Objectives: To evaluate the predicative power of the electrical risk score (ERS), a noninvasive and inexpensive test obtained by means of a standard 12-lead electrocardiogram (ECG), in a cohort of elderly patients who had undergone transcatheter aortic valve replacement (TAVR).

Methods: Survivors and non-survivors after TAVR at 1-year follow-up were compared in respect to the pre-procedural ERS as well as a number of other clinical and instrumental variables. ERS is composed of seven simple ECG markers: heart rate ( $>75 \mathrm{bpm})$; QRS duration ( $>110 \mathrm{~ms}$ ); left ventricular hypertrophy (Sokolow-Lyon criteria); delayed QRS transition zone ( $\geq$ V4); frontal QRS-T angle $\left(>90^{\circ}\right)$; long QT $_{\text {Bazett }}(>450 \mathrm{~ms}$ for men and $>460$ in women) or $\mathrm{JT}_{\text {Bazett }}$ (330 ms for men and $>340 \mathrm{~ms}$ for women); and long Tpeak to Tend interval $\left(\mathrm{T}_{\mathrm{p}-\mathrm{e}}\right)$ (>89 ms). The trial was registered in ClinicalTrials.gov as NCT03145376.

Results: A total of 40 patients were evaluated. During the follow-up, the all-cause mortality rate was $25 \%$ (ten patients) with $15 \%$ of cardiovascular death (six patients). The ERS was the strongest predictor of all-cause (odds ratio 3.73, 95\% CI: 1.44-9.66, $P<0.05$ ) or cardiovascular (odds ratio 3.95, 95\% CI: 1.09-14.27, $P<0.05$ ) mortality. Receiver operating characteristic curves showed that ERS had the widest significant sensitivity-specificity area under the curve (AUC) predicting all-cause (AUC: $0.855, P<0.05$ ) or cardiovascular mortality (AUC: 0.908 , $P<0.05$ ).

Conclusion: ERS seems to be a useful noninvasive tool able to stratify the risk of mortality in 1-year follow-up of TAVR patients. These findings, however, require larger trials to be confirmed.

Keywords: aortic stenosis, transaortic valve replacement, electrical risk score, mortality, Tpeak-Tend, QTc, frontal QRS-T angle

\section{Introduction}

Symptomatic senile degenerative aortic stenosis (AS) leads to a progressive deterioration of quality of life and it is associated with an elevated mortality. ${ }^{1}$ The most recent guidelines for the treatment of valvular heart disease identify the degenerative AS as the most common valve disease in Western countries, especially in the group aged over 65 years. $^{2-5}$ In its most severe form, AS represents a highly debilitating chronic disease characterized by symptoms such as precordial pain suggestive of angina, transient altered state of consciousness, or syncope, dyspnea and other heart failure symptoms secondary to a reduced stroke volume. After the onset of symptoms, in the case of no valve replacement procedure, the survival is less $50 \%$ within the first 2 years. ${ }^{6,7}$ Given that the conventional thoracic surgical approach is usually 
impossible in very elderly patients, transcatheter aortic valve replacement (TAVR) is often preferred even if this type of procedure suffers from a high perioperative risk. ${ }^{8}$ Up to now, a multidisciplinary evaluation (interventional cardiologist and expert in cardiovascular imaging, geriatrician, anesthesiologist etc.) is usually required to assess the patient's TAVR suitability. ${ }^{10,11}$ Indeed, the inclusion criteria for such a procedure are hemodynamic (mean aortic gradient, left ventricular ejection fraction, stroke volume index, etc.), anatomical (aortic valve and root morphology, etc.) and, obviously, clinical (symptoms, comorbidities, frailty, physical and cognitive functions, nutrition evaluation). Furthermore, TAVR is considered futile, and hence contraindicated, in those cases where the life expectancy is lower than 1 year due to comorbidities, despite a successful procedure, or when a chance of "survival with benefit" is lower than $25 \%$ at 2 years. ${ }^{10,11}$ However, it remains often difficult to exclude a potential benefit and, consequently, to establish the TAVR futility in a great percentage of patients, ${ }^{9}$ so that further implementation of the current strategies with additional variables is highly desirable. In such a context, the electrical risk score (ERS), ${ }^{12}$ an easy marker obtained from a standard 12-lead electrocardiogram (ECG), could represent a noninvasive and inexpensive useful clinical tool. Indeed, in senile AS, the prolonged systolic overload induced both anatomical and electrical remodeling ${ }^{13}$ and the major ECG findings associated with AS are also included in the ERS index (hypertrophy, intraventricular conduction delay, repolarization alterations). Aortic valve replacement can be associated with a reverse remodeling and more favorable outcome.

This actual retrospective study sought to investigate the possible utility of ERS in TAVR patients' selection. Briefly, we hypothesized that an increased ERS could be able to help the physician in identifying those patients with irreversible ventricular damage ${ }^{14-17}$ and, accordingly, help to predict a poor survival and, hence, a TAVR futility. To verify this hypothesis, we calculated the pre-procedural ERS in a cohort of patients who underwent TAVR and collected the overall and cardiovascular mortality data after 1-year follow-up.

\section{Methods and materials}

\section{Participants and protocol}

A total of 42 consecutive symptomatic patients with AS were evaluated for TAVR at Policlinico Umberto I University Hospital between March 2015 and September 2016. At the time of the first evaluation, patients' general data, a 12-lead ECG, a preoperative transthoracic Doppler echocardiographic evaluation (left ventricular telediastolic and telesistolic diameter, interventricular septum and posterior wall thickness, transvalvular aortic gradients/ regurgitation, aortic valve area, left ventricular ejection fraction, and left ventricular mass), and a full clinical assessment were recorded. The latter also included the following: the Mini-Mental State Examination (MMSE) to screen possible cognitive impairment; the Cumulative Illness Rating Scale (CIRS) to evaluate patients' comorbidities; the Activity of Daily Living (ADL) and Instrumental Activities of Daily Living (IADL) to evaluate the independence of the patients in everyday activities; the Mini-Nutritional Assessment (MNA) to estimate possible problems in the nutritional status; and the Short Form Health Survey-36 (SF-36) to assess the patient's quality of life, adjusted for age and sex among the Italian population. Furthermore, the Clinical Frailty Scale (CSF) was calculated to assess the impairment of patients in a scale from 1 (very fit) to 9 (terminally), considering data from the whole geriatric evaluation previously performed. ${ }^{18}$ Exclusion criteria for TAVR was a moderate-to-severe frailty score $(\geq 6){ }^{11}$

The endpoint, retrospectively analyzed, was the allcause and cardiovascular mortality at 1 year. The study was approved by the Ethical Committee of Azienda Universitaria Policlinico Umberto I. All participants provided their written informed consent. The trial was registered in ClinicalTrials. gov as NCT03145376.

\section{Electrocardiographic analysis}

Each enrolled patient had a stored resting 12-lead ECG (Esaote, model: MyCardioPad/XL 12 channels, Florence, Italy) available for the analysis (paper speed was $25 \mathrm{~mm} / \mathrm{s}$ and calibration $10 \mathrm{~mm} / \mathrm{mV}$ ). Those patients with ECG evidence of atrial flutter or II/III-degree atrioventricular block, pre-excitation, or paced rhythm were excluded from analysis.

Heart rate, QRS duration, left ventricular hypertrophy (Sokolow-Lyon criteria), delayed QRS transition zone, frontal QRS-T angle, long $\mathrm{QT}_{\text {Bazett }}$ or $\mathrm{JT}_{\text {Bazett, }}$ and long Tpeak to Tend interval $\left(\mathrm{T}_{\mathrm{p}-\mathrm{e}}\right.$ ) compose the ERS. ${ }^{11}$ In this score 1 and 0 were assigned respectively for an abnormal or normal ECG electrical value, and a score $\geq 4$ was considered predictive of high risk for mortality. ${ }^{12}$ Abnormal ECG data were considered as the following: a heart rate $>75 \mathrm{bpm}$, QRS duration $>110 \mathrm{~ms}$, the left ventricular hypertrophy, achieved with the Sokolow-Lyon criteria, the QRS transition $\geq 4$ th precordial lead (V4), the frontal 
QRS-angle $>90^{\circ}$, and $\mathrm{T}_{\mathrm{p}-\mathrm{e}}>89 \mathrm{~ms}^{12}$ Frontal QRS-T angle was calculated as the difference between $T$ wave and QRS axis; in case the difference between QRS and T axis was higher than $180^{\circ}$, QRT-T angle was calculated by subtracting these achieved degrees from $360^{\circ} .{ }^{19}$ Moreover, with regard to repolarization phase, we used the QT for QRS $<120 \mathrm{~ms}$ and JT for QRS for $>120 \mathrm{~ms}^{20,21}$ In both cases we corrected these two intervals by the Bazett method $\left(\mathrm{QT}_{\text {Bazett }}: \mathrm{QT}^{\mathrm{RR}} \mathrm{R}^{0.5}\right.$ and $\mathrm{JT}_{\text {Bazett: }}: \mathrm{JT} / \mathrm{RR}^{0.5}$ ). Respectively, a $\mathrm{QT}_{\text {Bazett }}$ interval $>450 \mathrm{~ms}$ for men and $>460 \mathrm{~ms}$ for women, a $\mathrm{JT}_{\text {Bazett }}$, a value $>330 \mathrm{~ms}$ for men and $>340 \mathrm{~ms}$ for women were considered prolonged and then a risk factor for mortality. ${ }^{22,23}$ An expert cardiologist analyzed all ECGs in our electrocardiographic laboratory calculating the ERS for each patient in a pre-procedural ECG.

\section{Statistical analysis}

We compared the baseline study data obtained before TAVR between the dead and surviving patients after 1-year follow-up. Normally distributed continuous variables are reported as mean and standard deviation and are compared using Student's $t$-test with Levene's test for homogeneity of variance. Non-normally distributed variables are expressed as median and inter-quartile range (IQR) and compared using the Mann-Whitney $U$ test. Categorical variables are presented as frequencies and percentage and compared using the chi-squared test. Receiver operating characteristic (ROC) curves were used to determine the sensitivity and specificity of the studied parameters predictive of all-cause and cardiovascular mortality, and areas under ROC curves and 95\% confidence intervals (CI) were calculated to compare the diagnostic efficiencies.

Uni- and multivariable forward (Wald) stepwise logistic regression analysis were used to determine the association between all-cause mortality or cardiovascular mortality and the other selected clinical, functional, echocardiographic, and electrical covariates included in the study model. Included covariates were: age, gender, body mass index, blood pressure, New York Heart Association (NYHA) class, MMSE, CIRS ADL, IADL, MNA, SF-36, aortic peak gradient, aortic mean gradient, ejection fraction, stroke volume index, cardiac index, left ventricular mass index, heart rate, QRS, QTc, JT ${ }_{C}$, $\mathrm{T}_{\mathrm{p}-\mathrm{e}}, \mathrm{QRS}-\mathrm{T}$ angle, $\mathrm{QRS}$ transition zone, electrocardiography left ventricular hypertrophy, and ERS.

\section{Results}

Forty-two patients underwent a complete evaluation; two patients were excluded from the TAVR procedure due to high level of comorbidities (Frailty score $\geq 6$ ).
Of the 40 patients included in the study, within the first year of follow-up, a total of 10 patients died (overall mortality rate $25 \%$ ). Specifically, six patients died from cardiovascular diseases (CVDs; two from heart failure worsening and four from stroke) (mortality rate 15\%), and four patients died for non-CVDs (three patients for respiratory infections and one for malignancy) (mortality rate 10\%). At the time of presentation, all patients were in III or IV NYHA functional class (Figure 1). Clinical and demographic characteristics are reported in Table 1, together with the type of valve implanted. In the pre-procedural evaluation, most of the clinical characteristics, functional assessment, and drug therapy were similar between survivors and non-survivors. Nevertheless, the survivors showed a significantly higher level of left ventricular ejection fraction, cardiac, and stroke volume indexes with regard to the subjects who died from cardiovascular issues (ejection fraction: $51 \pm 8$ vs $37 \% \pm 3 \%$, $P<0.001$; cardiac index: $2.2 \pm 0.3$ vs $1.9 \pm 0.3 \mathrm{~L} / \mathrm{m}^{2}, P<0.05$; stroke volume index: $33 \pm 5$ vs $\left.27 \pm 5 \mathrm{~mL} / \mathrm{m}^{2}, P<0.05\right)$ and of all-cause mortality (survivors vs deceased patients, ejection fraction: $51 \pm 8$ vs $38 \% \pm 5 \%, P<0.001$; cardiac index: $2.2 \pm 0.3$ vs $1.7 \pm 0.4 \mathrm{~L} / \mathrm{m}^{2}, P<0.05$; stroke volume index: $33 \pm 5$ vs $\left.27 \pm 4 \mathrm{~mL} / \mathrm{m}^{2}, P<0.05\right)$. The survivors showed a significantly lower level of peripheral resistances in comparison with the deceased patients from CVDs (survivors vs deceased patients: peripheral resistances: 1,983 \pm 561 vs $2,650 \pm 612$ arbitrary units, $P<0.05)$ and for all-cause mortality (survivors vs deceased patients: peripheral resistances: $1,983 \pm 561$ vs $2,723 \pm 544$ arbitrary units, $P<0.05)$. We did not find any differences between subjects for other echocardiographic data.

Regarding the ECG data (Table 2), the survivors showed lower electrical noninvasive parameters than the deceased subjects for cardiovascular or non-cardiovascular causes (Table 3). Particularly, in comparison with the deceased subjects for CVDs, the survivors reported a significant lower level of: $\mathrm{T}_{\mathrm{p} \text {-e }}$ (survivors vs deceased patients: $89 \pm 20$ vs $117 \pm 7 \mathrm{~ms}, P<0.05$ ), QRS transition zone (survivors vs deceased patients: V4 \pm 1 vs V5 $\pm 2, P<0.05)$, QRS-T angle (survivors vs deceased patients: -111 , IQR 181 vs 96, IQR $\left.228^{\circ}, P<0.05\right)$, electrocardiogram left ventricular hypertrophy (survivors vs deceased patients: $2 \pm 1$ vs $3 \pm 1 \mathrm{mV}$, $P<0.05$ ), and whole ERS (survivors vs CVD patients: $2 \pm 1$ vs $5 \pm 2$ score, $P<0.001$ ) (Figure 1). We pointed out almost the same pattern for the deceased subjects for all-cause mortality. Specifically, survivors had lower levels of: $\mathrm{T}_{\mathrm{p} \text {-e }}$ (survivors vs deceased patients: $89 \pm 20$ vs $110 \pm 11 \mathrm{~ms}, P<0.05)$, QRS transition zone (survivors vs deceased patients: V4 \pm 1 vs 

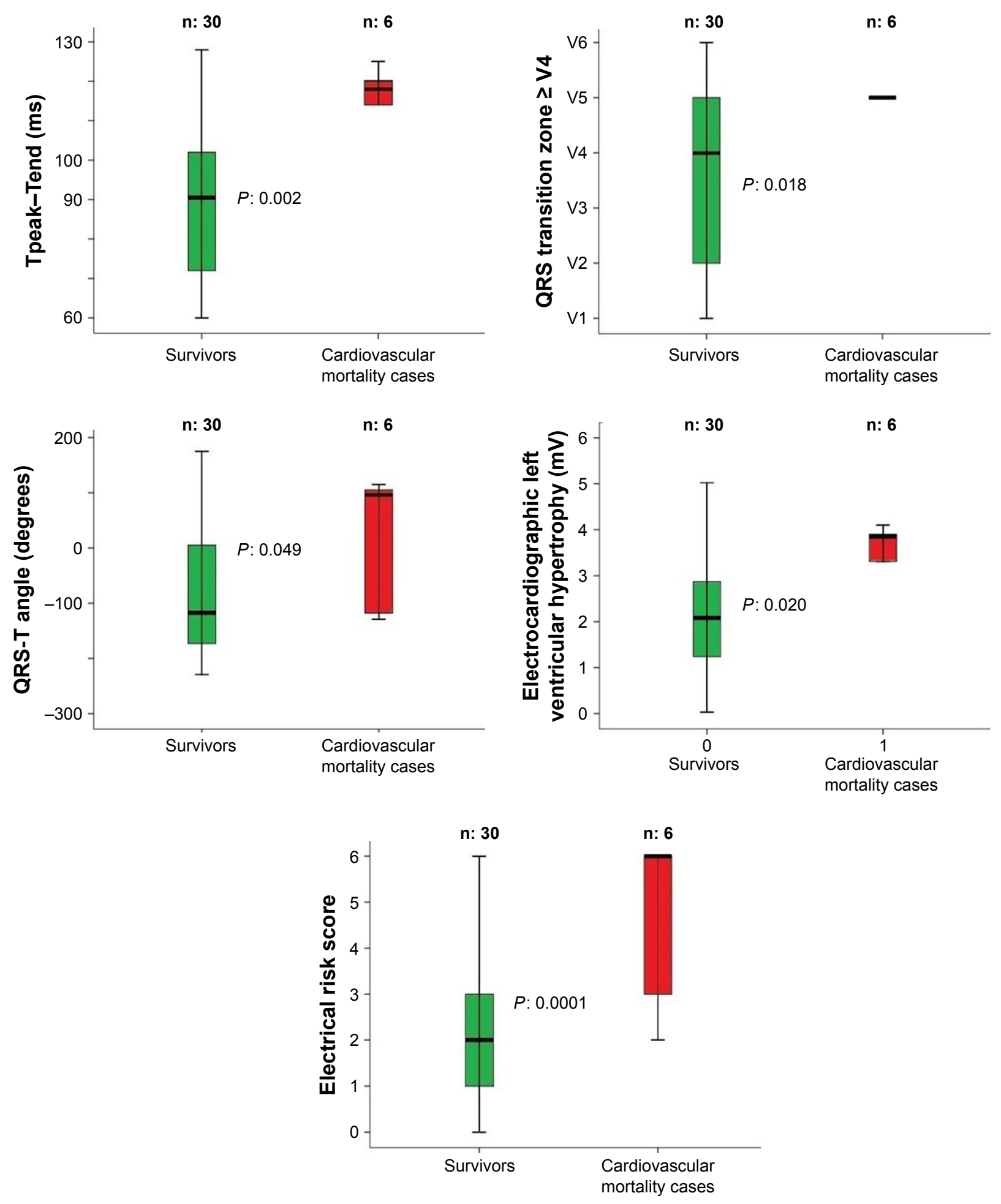

Figure I Comparison between survivors and cardiovascular mortality cases regarding the significant ECG data, obtained baseline.

Notes: In particular, the survivor subjects after I year of TAVR follow-up showed lower pre-TAVR: Tpeak-Tend segment, QRS transition zone, QRS-T angle, ECG left ventricular hypertrophy, and ERS. In the box plots, the central line represents the median distribution. Each box spans from 25 th to 75 th percentile points, and error bars extended from 10th to 90 th percentile points.

Abbreviations: ECG, electrocardiogram; ERS, electrical risk score; TAVR, transcatheter aortic valve replacement; V4, 4th precordial lead.

V5 $\pm 2, P<0.05)$, electrocardiogram left ventricular hypertrophy (survivors vs deceased patients: $2 \pm 1$ vs $3 \pm 1 \mathrm{mV}$, $P<0.05$ ), and ERS (survivors vs deceased patients: $2 \pm 1$ vs $4 \pm 2$ score, $P<0.001$ ) (Figure 2). All survivors had an ERS value lower than 4 , both considering the cardiovascular and non-cardiovascular mortality (Figure $3 \mathrm{~A}$ and $\mathrm{B}$ ).

The ERS variable showed the ROC curves with the highest sensitivity/specificity both for all-cause (AUC: 0.855 , 
Table I General characteristics of the transcatheter aortic valve replacement patients

\begin{tabular}{|c|c|}
\hline Analyzed data & $\mathrm{N}: 40$ \\
\hline Age, years & $8 \mathrm{I} \pm 7$ \\
\hline$M / F$ & $23 / 17$ \\
\hline $\mathrm{BMI}, \mathrm{kg} / \mathrm{m}^{2}$ & $26 \pm 4$ \\
\hline SBP, mmHg & $135 \pm 13$ \\
\hline $\mathrm{DBP}, \mathrm{mmHg}$ & $84 \pm 56$ \\
\hline Atrial fibrillation & $25(63)$ \\
\hline Complete left bundle branch block & $15(38)$ \\
\hline NYHA class III & $38(95)$ \\
\hline NYHA class IV & $2(5)$ \\
\hline Aortic peak gradient, mmHg & $82 \pm 20$ \\
\hline Aortic mean gradient, $\mathrm{mmHg}$ & $52 \pm 13$ \\
\hline Ejection fraction, $\%$ & $48 \pm 10$ \\
\hline Stroke volume index, $\mathrm{mL} / \mathrm{m}^{2}$ & $31 \pm 6$ \\
\hline Cardiac index, $\mathrm{L} / \mathrm{m}^{2}$ & $2.05 \pm 0.36$ \\
\hline Peripheral resistance, units & $2,168 \pm 639$ \\
\hline Left ventricular mass index, $g / \mathrm{m}^{2}$ & $|4| \pm 3 \mid$ \\
\hline Mini-mental state evaluation & $26 \pm 3$ \\
\hline Cumulative illness rating scale & $12 \pm 4$ \\
\hline Activity of day living & $5 \pm 1$ \\
\hline Instrumental activities of day living & $5 \pm 2$ \\
\hline Clinical frailty scale & $4 \pm 1$ \\
\hline Mini-nutritional assessment & $23 \pm 4$ \\
\hline \multicolumn{2}{|l|}{ Short form health survey } \\
\hline - Vitality & $45 \pm 14$ \\
\hline - Physical functioning & $21 \pm 19$ \\
\hline - Body pain & $58 \pm 29$ \\
\hline - General heath perceptions & $44 \pm 17$ \\
\hline - Physical role functioning & $|4 \pm 3|$ \\
\hline - Emotional role functioning & $38 \pm 46$ \\
\hline - Social role function & $45 \pm 18$ \\
\hline - Mental health & $58 \pm 15$ \\
\hline$\beta$-blockers, n (\%) & $35(88)$ \\
\hline Furosemide, $\mathrm{n}(\%)$ & $24(60)$ \\
\hline Calcium channel blockers, n (\%) & $16(40)$ \\
\hline ACE/sartan, $n(\%)$ & $13(63)$ \\
\hline Amiodarone, n (\%) & $2(5)$ \\
\hline Anticoagulants, $n$ (\%) & $25(63)$ \\
\hline \multicolumn{2}{|l|}{ Valve type } \\
\hline - CoreValve, n (\%) & $2(5 \%)$ \\
\hline - EdwardsXT, n (\%) & I (2.5\%) \\
\hline - Edwards Sapien 3, n (\%) & $19(47.5 \%)$ \\
\hline - CoreValveEvolut R, n (\%) & $12(30 \%)$ \\
\hline - Direct Flow, n (\%) & $5(12.5 \%)$ \\
\hline - Lotus, n (\%) & $2(5 \%)$ \\
\hline
\end{tabular}

Note: Data are expressed as mean \pm SD or number (n) of patients (\%).

Abbreviations: ACE, angiotensin-converting enzyme; BMl, body mass index; DBP, diastolic blood pressure; M/F, male/female; NYHA, New York Heart Association; SBP, systolic blood pressure.

$P<0.05$ ) and cardiovascular mortality (AUC: $0.908, P<0.05$ ) (Figure 4A and B). Other variables with statistical significance were $\mathrm{T}_{\mathrm{p}-\mathrm{e}}(P<0.05)$, QRS transition zone $(P<0.05)$, electrocardiography left ventricular hypertrophy $(P<0.05)$ for the all-cause mortality (Figure 4A) and all these electrical parameters and QTc $(P<0.05)$ and QRS-T angle $(P<0.05)$
Table 2 Electrocardiographic measures in the transcatheter aortic valve replacement patients

\begin{tabular}{|c|c|}
\hline Analyzed data & $N: 40$ \\
\hline Heart rate, bpm & $74 \pm 13$ \\
\hline QRS, ms & $115 \pm 25$ \\
\hline $\mathrm{QT}_{C}, \mathrm{~ms}$ & $460 \pm 46$ \\
\hline $\mathrm{JT}_{\mathrm{C}}, \mathrm{ms}$ & $334 \pm 44$ \\
\hline Tpeak-Tend, ms & $94 \pm 20$ \\
\hline QRS-T angle, ${ }^{\circ}$ & $-60(118)$ \\
\hline QRS transition zone & $4 \pm 1$ \\
\hline Electrocardiographic left ventricular & $3.4 \pm I .4$ \\
\hline \multicolumn{2}{|l|}{ hypertrophy, mV } \\
\hline Electrical risk score & $3.9 \pm 1.9$ \\
\hline
\end{tabular}

Note: Data are expressed as mean \pm SD or median (interquartile range).

for the cardiovascular mortality, too (Figure 4B). Hemodynamic variables reported extremely low accuracy values for all-cause or cardiovascular mortality; aortic valve gradients or left ventricular mass index (LVMI) AUC did not report any statistical significance.

Univariable logistic regression analysis reported a significant relationship between all-cause mortality and ERS $(P<0.05)$, ejection fraction $(P<0.05)$, ECG hypertrophy $(P<0.05)$, QRS transition zone $(P<0.05), \mathrm{T}_{\mathrm{p}-\mathrm{e}}$ $(P<0.05)$ (Figure 5$)$ and between cardiovascular mortality and ERS $(P<0.05)$ and ejection fraction $(P<0.05)$ (Figure 5). Multivariable logistic regression analysis only selected ERS as the significant risk factor for all-cause (odds ratio 3.73, 95\% CI: $1.44-9.66, P<0.05)$ or cardiovascular mortality (odds ratio 3.95, 95\% CI: 1.09-14.27, $P<0.05$ ) (Figure 5).

\section{Discussion}

The most important finding of our study was that a simple and almost inexpensive score obtained from the standard 12-lead electrocardiogram is significantly higher in TAVR subjects with high risk of mortality at 1-year follow-up. Thus, we could reasonably consider the ERS as a useful tool in managing TAVR patients' selection. In particular, our data

Table 3 Electrocardiographic abnormal markers in the transcatheter aortic valve replacement patients

\begin{tabular}{ll}
\hline Analyzed data & $\mathbf{N}: \mathbf{4 0}$ \\
\hline Heart rate $>75$ & $\mathrm{I} 5(38)$ \\
$\mathrm{QRS}>\mathrm{II} \mathrm{I} \mathrm{ms}$ & $20(50)$ \\
$\mathrm{QT}_{\text {Bazett }}>450$ or $>460 \mathrm{~ms}$ or $\mathrm{JT}_{\text {Bazett }}>330$ or $>340 \mathrm{~ms}$ & $2 \mathrm{I}(53)$ \\
Tpeak-Tend $>89 \mathrm{~ms}$ & $23(58)$ \\
QRS-T angle $>90^{\circ}$ & $\mathrm{I}(30)$ \\
QRS transition zone $\geq \mathrm{V} 4$ & $\mathrm{I} 5(38)$ \\
Electrocardiographic left ventricular hypertrophy & $\mathrm{I}(25)$ \\
Electrical risk score $\geq 4$ & $5(13)$ \\
\hline
\end{tabular}

Notes: Data are presented as cases (\%), QTc $>450 \mathrm{~ms}$ in men and $>460 \mathrm{~ms}$ in women; $\mathrm{JT}_{\text {Bazett }}>330$ in men or $>340 \mathrm{~ms}$ in women.

Abbreviation: $\mathrm{V} 4$, 4th precordial lead. 

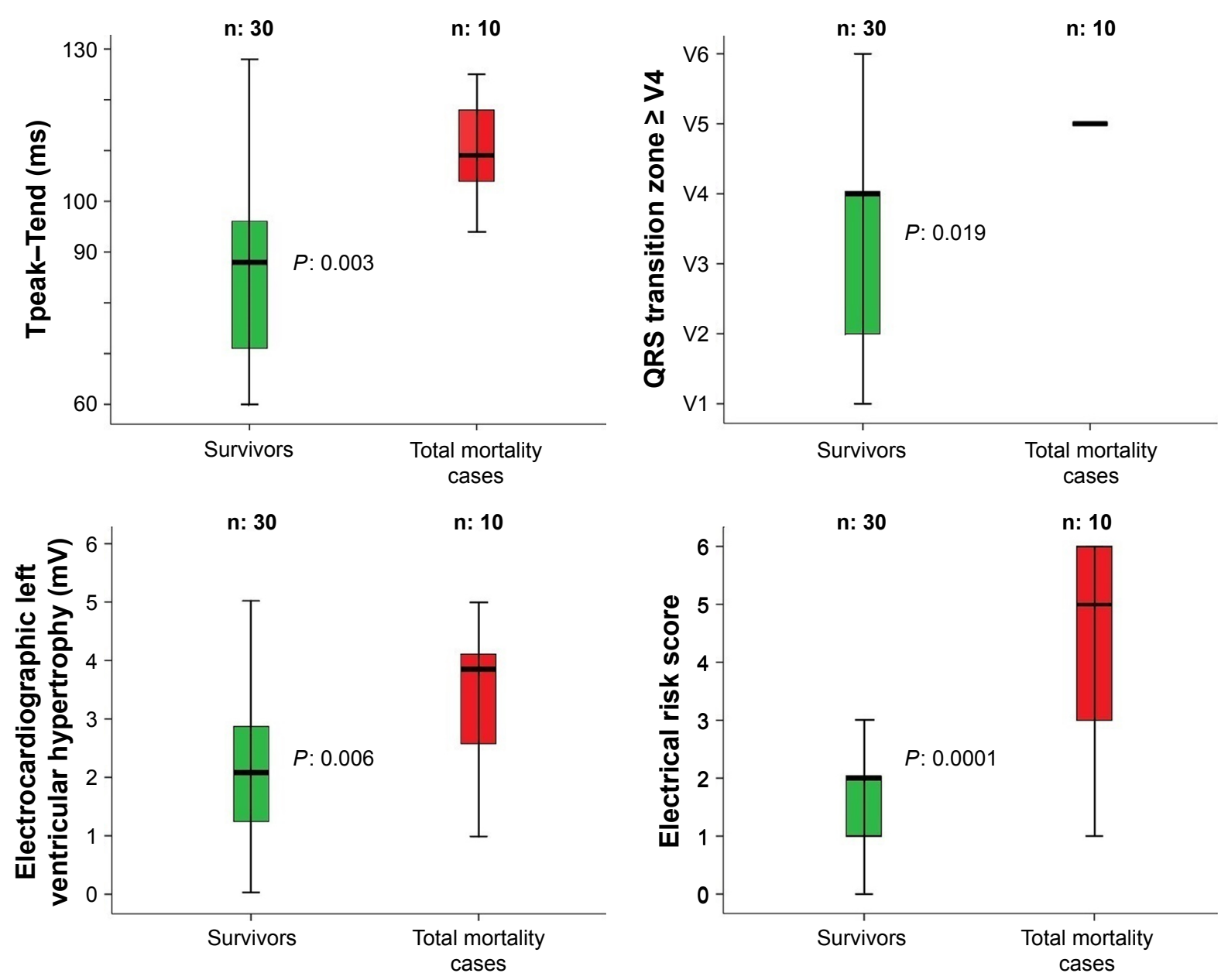

Figure 2 Comparison between survivors and total mortality cases regarding the significant ECG data, obtained baseline.

Notes: In particular, the survivor subjects after I year of TAVR follow-up showed a significant lower pre-TAVR: Tpeak-Tend segment, QRS transition zone, electrocardiogram left ventricular hypertrophy, and ERS. In the box plots, the central line represents the median distribution. Each box spans from 25 to 75 th percentile points, and error bars extended from 10 to 90 th percentile points.

Abbreviations: ECG, electrocardiogram; ERS, electrical risk score; TAVR, transcatheter aortic valve replacement.

show that all surviving patients had an ERS value below 4 while half of the patients who died showed an ERS equal or higher than 4. The ROC curves showed that the ERS had the widest significant sensitivity-specificity AUC predicting all-cause or cardiovascular mortality and, even, the multivariable forward stepwise logistic regression analysis selected the ERS as the most significant risk factor of the all-cause or cardiovascular mortality and it excluded the ejection fraction or stroke volume index as risk factors, which are the usual markers with the more reliable level of predictively. ${ }^{14-17}$

The ERS is composed of seven different electrocardiographic markers, each of them an expression of electrical and structural cardiac damage. In such context, it is likely that the noninvasive ECG variables are earlier markers of mortality risk given that they depend on imbalanced neuro-autonomic control (heart rate, QTc, and $\mathrm{T}_{\mathrm{pee}}$ ), on the repolarization alterations (QTc, QRS-angle, and $\mathrm{T}_{\mathrm{p}-\mathrm{e}}$ ) and on cardiac hypertrophy (QTc, QRS-angle, QRS transition, and $\mathrm{T}_{\mathrm{p}-\mathrm{e}}$ ), all of them known markers of poor outcome in chronic heart failure and coronary artery disease.

Between the seven noninvasive ECG markers, included in the ERS, heart rate is the simplest and apparently trivial. We can consider heart rate with a double clinical meaning: firstly as a mere index of heart failure decompensation and secondly as an instantaneous marker of autonomic cardiovascular control. Indeed, in AS patients the sympathetic control prevails on the vagal and baroreceptor activity thus leading to an increase of heart rate, of myocardial oxygen demand, and relative ischemia with a tendency to ventricular and supraventricular arrhythmias. A great number of observations indicates that the increase of resting heart rate was an important risk factor for mortality in the chronic heart failure. ${ }^{24-26}$ In contrast, the QTc or JTc, and $\mathrm{T}_{\mathrm{p}-\mathrm{e}}$ are markers of ventricular repolarization delay and ventricular arrhythmia tendency. In particular, prolonged 
A

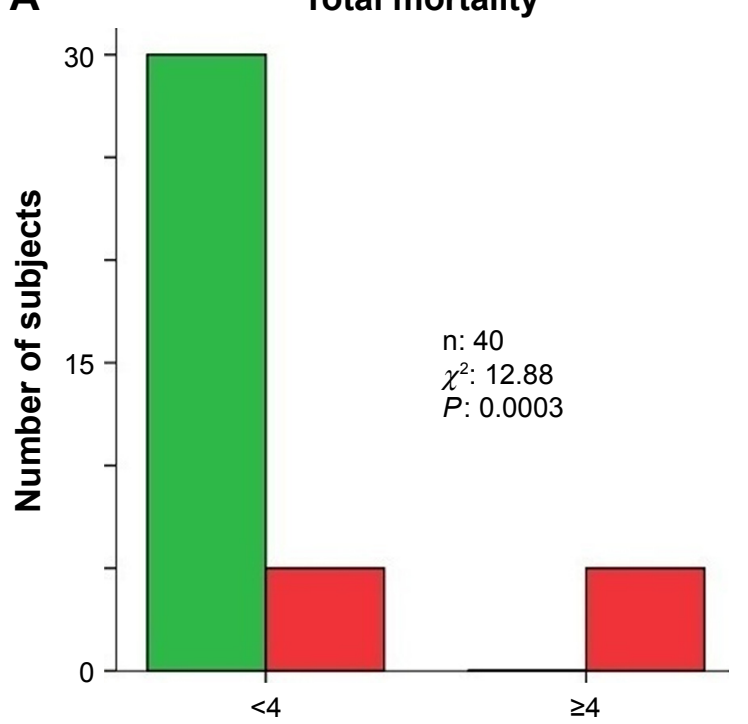

\section{B Cardiovascular mortality}

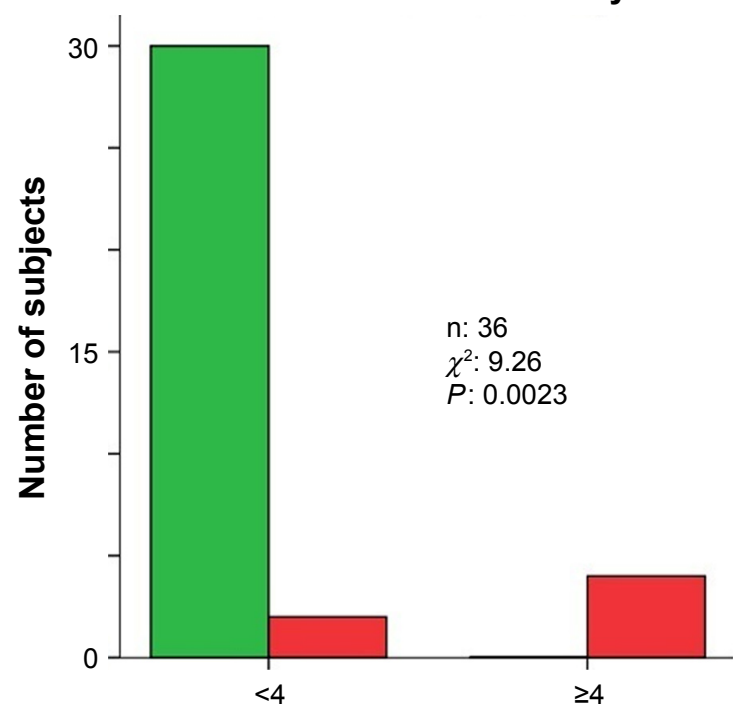

Electrical risk score

Survivors $\square$ Deceased subjects

Figure 3 We reported the total (A) and cardiovascular (B) mortality in the subjects with less or equal or higher than four electrical risk score in the study subjects. Notes: In the B study population, we excluded the subject deceased for non-CVD. Statistical comparison was obtained by chi-squared test.

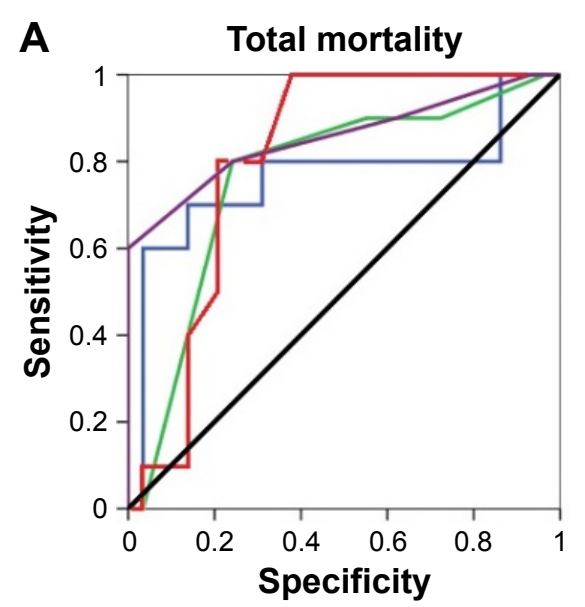

\begin{tabular}{llllll}
\hline $\begin{array}{l}\text { Test result } \\
\text { variable }\end{array}$ & Area & Std error & $\begin{array}{l}\text { Asymptotic } \\
\text { sig }\end{array}$ & $\begin{array}{l}\text { Asymptotic 95\% } \\
\text { confidence interval }\end{array}$ \\
\cline { 4 - 6 } & & & & Lower & Upper \\
\hline Tpeak-Tend & 0.807 & 0.068 & 0.004 & 0.673 & 0.941 \\
$\begin{array}{l}\text { QRS transition } \\
\text { zone } \geq \text { V4 }\end{array}$ & 0.766 & 0.089 & 0.013 & 0.591 & 0.940 \\
$\begin{array}{l}\text { Electrocardiographic } \\
\text { left ventricular }\end{array}$ & 0.762 & 0.108 & 0.015 & 0.550 & 0.974 \\
$\begin{array}{l}\text { hypertrophy } \\
\begin{array}{l}\text { Electrical risk score } \\
\hline\end{array}\end{array}$ & 0.855 & 0.083 & 0.001 & 0.962 & 1.000 \\
\hline
\end{tabular}

\section{ROC curves}

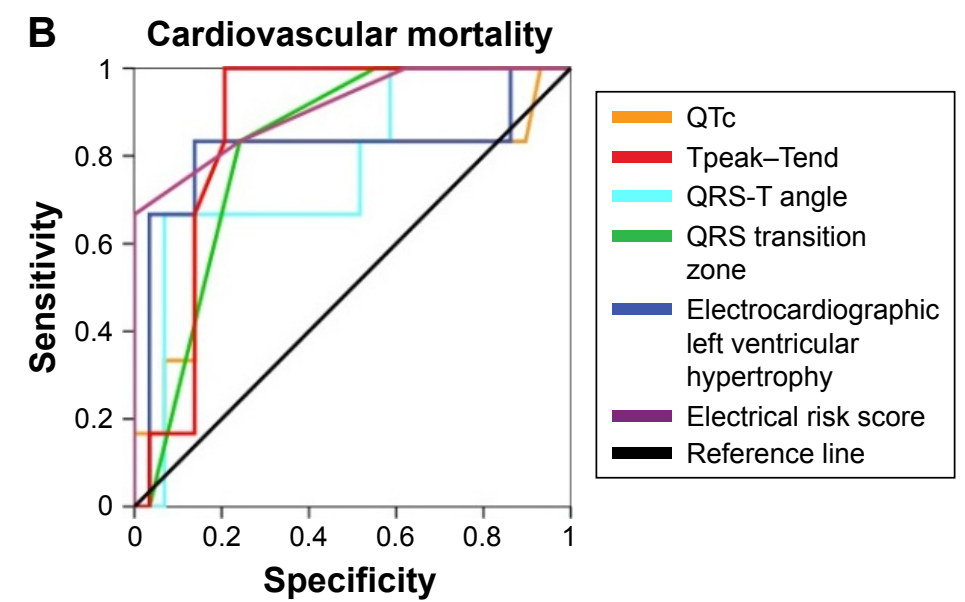

\begin{tabular}{|c|c|c|c|c|c|}
\hline \multirow[t]{2}{*}{$\begin{array}{l}\text { Test result } \\
\text { variable }\end{array}$} & \multirow[t]{2}{*}{ Area } & \multirow[t]{2}{*}{ Std error } & \multirow[t]{2}{*}{$\begin{array}{l}\text { Asymptotic } \\
\text { sig }\end{array}$} & \multicolumn{2}{|c|}{$\begin{array}{l}\text { Asymptotic } 95 \% \\
\text { confidence interval }\end{array}$} \\
\hline & & & & Lower & Upper \\
\hline QTC & 0.761 & 0.132 & 0.046 & 0.502 & 1.000 \\
\hline Tpeak-Tend & 0.862 & 0.061 & 0.006 & 0.742 & 0.983 \\
\hline QRS-T angle & 0.770 & 0.107 & 0.040 & 0.561 & 0.979 \\
\hline $\begin{array}{l}\text { QRS transition } \\
\text { zone } \geq \mathrm{V} 4\end{array}$ & 0.819 & 0.074 & 0.015 & 0.673 & 0.965 \\
\hline $\begin{array}{l}\text { Electrocardiographic } \\
\text { left ventricular } \\
\text { hypertrophy }\end{array}$ & 0.810 & 0.129 & 0.018 & 0.558 & 1.000 \\
\hline Electrical risk score & 0.908 & 0.072 & 0.002 & 0.766 & 1.000 \\
\hline
\end{tabular}

Figure 4 Receiver operating characteristic curve (ROC) analysis showing that the electrical risk score (ERS) was the best predictor of total (A) or cardiovascular (B) mortality in TAVR patients.

Abbreviations: sig, significance; std, standard; TAVR, transcatheter aortic valve replacement. 


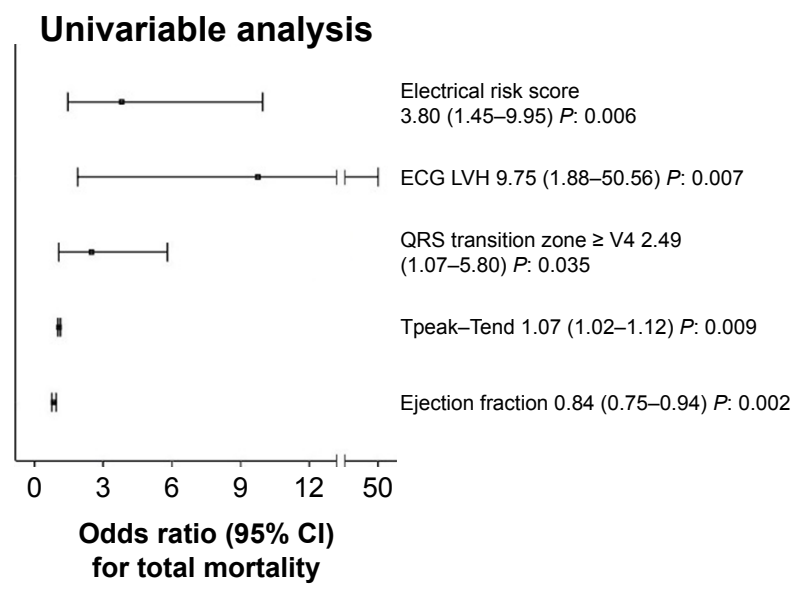

Univariable analysis

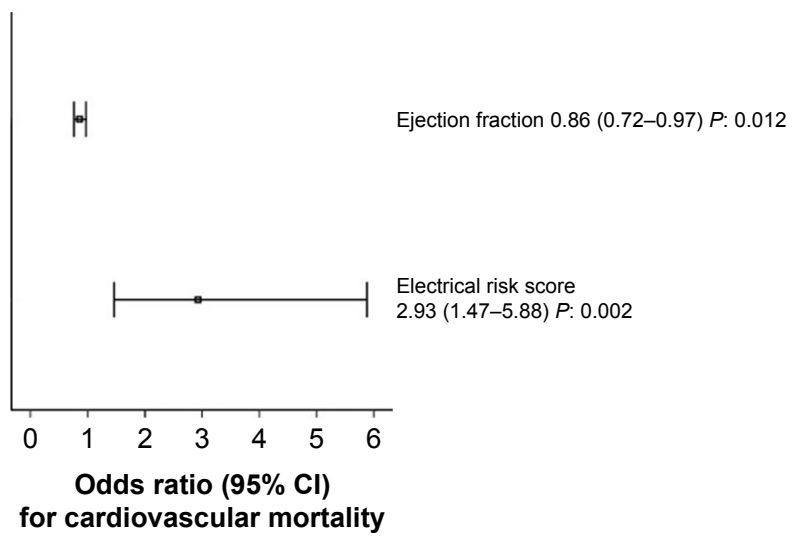

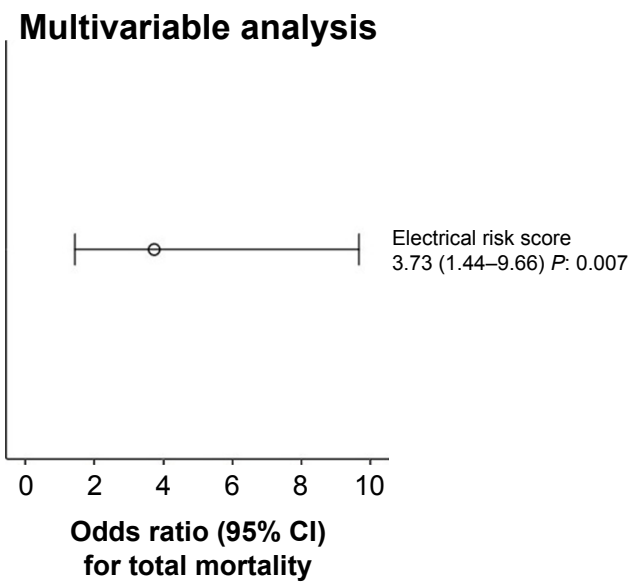

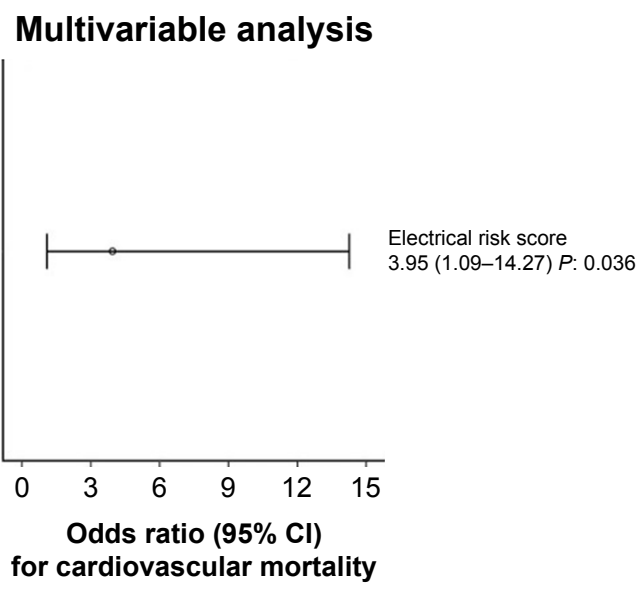

Figure 5 Odds ratio for electrical risk score, electrocardiographic left ventricular hypertrophy (ECG LVH), QRS transition zone $\geq$ V4, Tpeak-Tend interval, ejection fraction in respect to total and cardiovascular mortality in uni- or multivariable analysis.

Abbreviation: V4, 4th precordial lead.

QTc and $\mathrm{T}_{\mathrm{p}-\mathrm{e}}$ express an excessive length of the action's potential duration, the ventricular damage, and loss of ionic channel controls. Moreover, the cardiac hypertrophy and heart failure induce an abnormal potassium channel function and a reduction of the repolarization reserve. ${ }^{27}$ On the other hand, although controversial, ${ }^{28,29} \mathrm{~T}_{\mathrm{p}-\mathrm{e}}$ is thought to be associated with the apico-basal and transmural action potential duration gradients ${ }^{30}$ and influenced by autonomic nervous system in several CVD settings. ${ }^{31-33}$ Both QTc and $\mathrm{T}_{\mathrm{p}-\mathrm{e}}$ increase in cases of cardiac hypertrophy, ischemia, and heart failure, and they represent known risk factors of all-cause cardiovascular mortality. ${ }^{34-39}$ In particular, a relationship was observed between outcome and QTc in severe AS with low flow, low gradient, reduced ejection fraction, and mortality. ${ }^{40}$ Obviously, the QTc measurement does not make any sense in the presence of complete left bundle branch block and, in such a case, the use of the JTc interval is more appropriate. ${ }^{20,21,41}$ The QRS duration, the transition QRS zone, the electrical left ventricular hypertrophy, and the frontal QRS-T angle are influenced by myocardial mass and fibrosis. Particularly, the QRS duration, a marker of intraventricular conduction, was independently related to all-cause mortality, ${ }^{42}$ especially in patients with severe AS and low flow, low gradient and reduced ejection fraction. ${ }^{43}$ In our study, half of the subjects reported an increase of QRS duration, more than $110 \mathrm{~ms}$, a cutoff assigned in the original paper by Aro et al on ERS. ${ }^{12}$ The transition zone at V4 or leftward of V4 on chest, otherwise known as the clockwise rotation (Minnesota code: 9-4-2) ${ }^{44}$ was recently associated with an increase of all-cause ${ }^{45,46}$ or cardiovascular mortality ${ }^{45}$ or to a heart failure ${ }^{46}$ in subjects apparently free from CVD. Another study reported that the delayed transition zone was related to the left ventricular mass and that this electrical marker, independently from the left ventricular ejection fraction, was a risk predictor of sudden cardiac death. ${ }^{12}$ In our study, $38 \%$ of subjects showed the delayed transitional zone. In a paper dealing with this electrical marker, authors preferred to exclude the subjects with left or right bundle branch block, because in their study the intraventricular block could be considered a confounding factor. In that study, the authors analyzed the possible predictive 
role of the different QRS transition zones (counterclockwise, clockwise and no rotation) on mortality. ${ }^{46}$ Subjects with counterclockwise rotation showed a lower risk of mortality; obviously in subjects with the right bundle branch block, we can always observe counterclockwise rotation, with a deep S in V2 and therefore that electrocardiographic picture could be interpreted as a favorable condition (false negative). To exclude possible false negative results, the authors decided not to include all intraventricular conduction disturbances. In contrast, in our study we observed only subjects with left bundle branch block (38\%) and clockwise rotation. Another marker, most likely the most popular one, included in the ERS is the left ventricular Sokolow-Lyon voltage criteria. It is a weak maker of left hypertrophy degree, ${ }^{47}$ but it is independently associated with the severity of valvulopathy ${ }^{48}$ and it is predictive of poor prognosis in patients with asymptomatic AS. ${ }^{49}$ Lastly, the frontal QRS-T angle higher than $90^{\circ}$, a measure of both depolarization and repolarization disturbance, was studied in populations with various risk patterns of cardiovascular or all-cause mortality, ${ }^{50,51}$ but not particularly in AS elderly patients. However, the pressure overload, ${ }^{51,52}$ the left ventricular hypertrophy, ${ }^{53}$ and aging ${ }^{54}$ were reported as the most important causes of this electrical marker increase. Obviously, for this reason our data detected an increase of this marker in the AS in 30\% of subjects.

In conclusion, the power of the ERS was not only a simple sum of different electrocardiographic markers, but it could be an inexpensive multilevel cardiac diagnostic tool capable of investigating the myocardial damage in the degenerative AS.

\section{Study limitations}

The small number of patients enrolled together with the low number of events represent an obvious limitation that allows us to suggest, rather than to affirm, that the ERS might improve the TAVR patients' selection. Larger studies would be strongly encouraged to confirm our pilot observations.

Other possible limitation that should be acknowledged refers to Bazett's formula for QT correction. Indeed, although routinely used in clinical practice, it overcorrects at elevated heart rates and under corrects at heart rates below 60 beats per minute (bpm) and hence is not an ideal correction. Fridericia's correction is more accurate than Bazett's correction in subjects with such altered heart rates. However, it should be highlighted that all patients evaluated in the present study had a heart rate between 60 and $90 \mathrm{bpm}$. Finally, other well-known electrical risk abnormalities (such as $\mathrm{P}$ wave duration, deep terminal negativity of the $\mathrm{P}$ wave, QRS fragmentation, ST segment depression and elevation, inverted $\mathrm{T}$ waves, $\mathrm{T}$ wave alternans, premature ventricular contractions) were not evaluated in the present study.

\section{Acknowledgment}

This study was funded by University "La Sapienza"; ClinicalTrials.gov number, NCT03145376.

\section{Disclosure}

The authors report no conflicts of interest in this work.

\section{References}

1. Kleczyński P, Bagieński M, Dziewierz A, et al. Twelve-month quality of life improvement and all-cause mortality in elderly patients undergoing transcatheter aortic valve replacement. Int J Artif Organs. 2016;39(8):444-449.

2. Vahanian A, Alfieri O, Andreotti F, et al. Guidelines on the management of valvular heart disease (version 2012). The Joint Task Force on the Management of Valvular Heart Disease of the European Society of Cardiology (ESC) and the European Association for Cardio-Thoracic Surgery (EACTS). Eur Heart J. 2012;33:2451-2496.

3. Osnabrugge RL, Mylotte D, Head SJ, et al. Aortic stenosis in the elderly: disease prevalence and number of candidates for transcatheter aortic valve replacement: a meta-analysis and modeling study. $J \mathrm{Am}$ Coll Cardiol. 2013;62(11):1002-1012.

4. European Society of Cardiology. Guidelines on the management of valvular heart disease. Eur J Cardiothorac Surg. 2012;42(4):S1-S44.

5. Nishimura RA, Otto CM, Bonow RO, et al. 2014 AHA/ACC Guideline for the Management of Patients with Valvular Heart Disease: a report of the American College of Cardiology/American Heart Association Task Force on Practice Guidelines. Circulation. 2014;129(23):e521-e643.

6. Schwarz F, Baumann P, Manthey J, et al. The effect of aortic valve replacement on survival. Circulation. 1982;66(5):1105-1110.

7. Makkar RR, Fontana GP, Jilaihawi H, et al. Transcatheter aorticvalve replacement for inoperable severe aortic stenosis. $N$ Engl J Med Overseas Ed. 2012;366(18):1696-1704.

8. Leon MB, Smith CR, Mack M, et al. Transcatheter aortic-valve implantation for aortic stenosis in patients who cannot undergo surgery. $N$ Engl J Med Overseas Ed. 2010;363(17):1597-1607.

9. Reynolds MR, Magnuson EA, Wang K, et al. Health-related quality of life after transcatheter or surgical aortic valve replacement in highrisk patients with severe aortic stenosis: results from the PARTNER (Placement of AoRTic TraNscathetER Valve) Trial (Cohort A). J Am Coll Cardiol. 2012;60(6):548-558.

10. Lindman BR, Alexander KP, O'Gara PT, Afilalo J. Futility, benefit, and transcatheter aortic valve replacement. JACC Cardiovasc Interv. 2014;7(7):707-716.

11. Otto CM, Kumbhani DJ, Alexander KP, et al. ACC expert consensus decision pathway for transcatheter aortic valve replacement in the management of adults with aortic stenosis: a report of the American College of Cardiology task force on clinical expert consensus documents. J Am Coll Cardiol. 2017;69(10):1313-1346.

12. Aro AL, Reinier K, Rusinaru C, et al. Electrical risk score beyond the left ventricular ejection fraction: prediction of sudden cardiac death in the Oregon Sudden Unexpected Death Study and the Atherosclerosis Risk in Communities Study. Eur Heart J. 2017;38(40):3017-3025.

13. Magalhaes MA, Koifman E, Torguson R. Outcome of left-sided cardiac remodeling in severe aortic stenosis patients undergoing transcatheter aortic valve implementation. Am J Cardiol. 2015;116(4):595-603.

14. Douglas PS, Leon MB, Mack MJ, et al. Longitudinal hemodynamics of transcatheter and surgical aortic valves in the PARTNER Trial. JAMA Cardiol. 2017;2(11):1197-1206.

15. Baron SJ, Arnold SV, Herrmann HC, et al. Impact of ejection fraction and aortic valve gradient on outcomes of transcatheter aortic valve replacement. J Am Coll Cardiol. 2016;67(20):2349-2358. 
16. Pibarot $P$, Clavel MA. Doppler echocardiographic quantitation of aortic valve stenosis: a science in constant evolution. J Am Soc Echocardiogr. 2016;29(10):1019-1022.

17. Carreras ET, Kaneko T, Ramirez-del Val F, et al. Impact of flow, gradient, and left ventricular function on outcomes after transcatheter aortic valve replacement. Catheter Cardiovasc Interv. 2018;91(4):1039.

18. Rockwood K, Song X, MacKnight C. A global clinical measure of fitness and frailty in elderly people. Can Med Assoc J. 2005;173(5): 489-495.

19. Chua KCM, Teodorescu C, Reinier K, et al. Wide QRS-T angle on the 12-lead ECG as a predictor of sudden death beyond the LV ejection fraction. J Cardiovasc Electrophysiol. 2016;27(7):833-839.

20. Rautaharju PM, Zhang Z-M, Prineas R, Heiss G. Assessment of prolonged QT and JT intervals in ventricular conduction defects. $\mathrm{Am} \mathrm{J}$ Cardiol. 2004;93(8):1017-1021.

21. Crow RS, Hannan PJ, Folsom AR. Prognostic significance of corrected QT and corrected JT interval for incident coronary heart disease in a general population sample stratified by presence or absence of wide QRS complex: the ARIC Study with 13 years of follow-up. Circulation. 2003;108(16):1985-1989.

22. Rautaharju PM, Surawicz B, Gettes LS, et al. AHA/ACCF/HRS recommendations for the standardization and interpretation of the electrocardiogram: part IV: the ST segment, T and U waves, and the QT interval: a scientific statement from the American Heart Association Electrocardiography and Arrhythmias Committee, Council on Clinical Cardiology; the American College of Cardiology Foundation; and the Heart Rhythm Society. Endorsed by the International Society for Computerized Electrocardiology. J Am Coll Cardiol. 2009;53(11):982-991.

23. Shimizu H, Ohnishi Y, Inoue T, Yokoyama M. QT and JT dispersion in patients with monomorphic or polymorphic ventricular tachycardia/ ventricular fibrillation. J Electrocardiol. 2001;34(2):119-125.

24. Lechat P, Hulot JS, Escolano S, et al. Heart rate and cardiac rhythm relationships with bisoprolol benefit in chronic heart failure in CIBIS II Trial. Circulation. 2001;103(10):1428-1433.

25. Pocock SJ, Wang D, Pfeffer MA, et al. Predictors of mortality and morbidity in patients with chronic heart failure. Eur Heart J. 2006; 27(1):65-75.

26. Rossi A, Temporelli PL, Cicoira M, et al. Beta-blockers can improve survival in medically-treated patients with severe symptomatic aortic stenosis. Int J Cardiol. 2015;190:15-17.

27. Roden DM. Long QT syndrome: reduced repolarization reserve and the genetic link. J Intern Med. 2006;259(1):59-69.

28. Antzelevitch C, Shimizu W, Yan GX, et al. The M cell: its contribution to the ECG and to normal and abnormal electrical function of the heart. J Cardiovasc Electrophysiol. 1999;10(8):1124-1152.

29. Opthof T, Coronel R, Wilms-Schopman FJG, et al. Dispersion of repolarization in canine ventricle and the electrocardiographic $\mathrm{T}$ wave: Tp-e interval does not reflect transmural dispersion. Heart Rhythm. 2007;4(3):341-348.

30. Arteyeva NV, Goshka SL, Sedova KA, Bernikova OG, Azarov JE. What does the $T_{\text {peak }}-T_{\text {end }}$ interval reflect? An experimental and model study. J Electrocardiol. 2013;46(4):296.e1-296.e8.

31. Piccirillo G, Magrì D, Pappadà MA, et al. Autonomic nerve activity and the short-term variability of the Tpeak-Tend interval in dogs with pacing-induced heart failure. Heart Rhythm. 2012;9(12):2044-2050.

32. Piccirillo G, Rossi P, Mitra M, et al. Indexes of temporal myocardial repolarization dispersion and sudden cardiac death in heart failure: any difference? Ann Noninvasive Electrocardiol. 2013;18(2):130-139.

33. Piccirillo G, Moscucci F, Pascucci M, et al. Influence of aging and chronic heart failure on temporal dispersion of myocardial repolarization. Clin Interv Aging. 2013;8:293-300.

34. Beinart R, Zhang Y, Lima JA, et al. The QT interval is associated with incident cardiovascular events: the MESA study. $J$ Am Coll Cardiol. 2014;64(20):2111-2119.

35. Ahn SV, Kim HC, Hur NW, et al. Relationship between corrected QT interval and cardiovascular risk factors in young healthy adults: the Kangwha study. J Prev Med Public Health. 2006;39(6):455-461.
36. Ishikawa J, Ishikawa S, Kario K. Relationships between the QTc interval and cardiovascular, stroke, or sudden cardiac mortality in the general Japanese population. J Cardiol. 2015;65(3):237-242.

37. Dekker JM, Schouten EG, Klootwijk P, Pool J, Kromhout D. Association between QT interval and coronary heart disease in middleaged and elderly men. The Zutphen Study. Circulation. 1994;90(2): 779-785.

38. Tse G, Gong M, Wong WT, et al. The $\mathrm{T}_{\text {peak }}-\mathrm{T}_{\text {end }}$ interval as an electrocardiographic risk marker of arrhythmic and mortality outcomes: A systematic review and meta-analysis. Heart Rhythm. 2017;14(8): 1131-1137.

39. Bachmann TN, Skov MW, Rasmussen PV, et al. Electrocardiographic Tpeak-Tend interval and risk of cardiovascular morbidity and mortality: results from the Copenhagen ECG study. Heart Rhythm. 2016;13(4):915-924.

40. Dahou A, Toubal O, Clavel MA, et al. Relationship between QT interval and outcome in low-flow low-gradient aortic stenosis with low left ventricular ejection fraction. $J$ Am Heart Assoc. 2016;5(10):e003980.

41. Tabatabaei P, Keikhavani A, Haghjoo M, et al. Assessment of QT and JT intervals in patients with left bundle branch block. Res Cardiovasc Med. 2016;5(2):e31528.

42. Prihadi EA, Leung M, Vollema EM, et al. Prevalence and prognostic relevance of ventricular conduction disturbances in patients with aortic stenosis. Am J Cardiol. 2017;120(12):2226-2232.

43. Sebag FA, Lellouche N, Chaachoui N, Dubois-Rande J-L, Gueret P, Monin J-L. Prevalence and clinical impact of QRS duration in patients with low-flow/low-gradient aortic stenosis due to left ventricular systolic dysfunction. Eur J Heart Fail. 2014;16(6):639-647.

44. Prineas R, Crow RS, Zhang Z-M. The Minnesota Code Manual of Electrocardiographic Findings. London: Springer-Verlag; 2010.

45. Bradford N, Shah AJ, Usoro A, Haisty WK, Soliman EZ. Abnormal electrocardiographic QRS transition zone and risk of mortality in individuals free of cardiovascular disease. Europace. 2015;17(1):131-136.

46. Patel S, Kwak L, Agarwal SK, et al. Counterclockwise and clockwise rotation of QRS transitional zone: prospective correlates of change and time-varying associations with cardiovascular outcomes. $J$ Am Heart Assoc. 2017;6(11): pii:e006281.

47. Sjöberg S, Sundh F, Schlegel T, et al. The relationship between electrocardiographic left ventricular hypertrophy criteria and echocardiographic mass in patients undergoing transcatheter aortic valve replacement. J Electrocardiol. 2015;48(4):630-636.

48. Greve AM, Gerdts E, Boman K, et al. Differences in cardiovascular risk profile between electrocardiographic hypertrophy versus strain in asymptomatic patients with aortic stenosis (from SEAS data). Am J Cardiol. 2011;108(4):541-547.

49. Greve AM, Boman K, Gohlke-Baerwolf C, et al. Clinical implications of electrocardiographic left ventricular strain and hypertrophy in asymptomatic patients with aortic stenosis: the Simvastatin and Ezetimibe in Aortic Stenosis study. Circulation. 2012;125(2):346-353.

50. Oehler A, Feldman T, Henrikson CA, Tereshchenko LG. QRS-T angle: a review. Ann Noninvasive Electrocardiol. 2014;19(6):534-542.

51. Zhong G, Wang Y, Zhang Y, Zhao Y. Association between benzodiazepine use and dementia: a meta-analysis. PLoS One. 2015;10(5): e0127836.

52. Atsma F, Bartelink M-LEL, van der Schouw YT, Kors JA, Grobbee DE. Elevated blood pressure and electrocardiographic frontal $\mathrm{T}$ axis and spatial QRS-T angle changes in postmenopausal women. J Electrocardiol. 2008;41(4):360-364.

53. Man S, Rahmattulla C, Maan AC, et al. Role of the vectorcardiogramderived spatial QRS-T angle in diagnosing left ventricular hypertrophy. J Electrocardiol. 2012;45(2):154-160.

54. van der Ende MY, Siland JE, Snieder H, van der Harst P, Rienstra M. Population-based values and abnormalities of the electrocardiogram in the general Dutch population: The LifeLines Cohort Study. Clin Cardiol. 2017;40(10):865-872. 
Clinical Interventions in Aging

\section{Publish your work in this journal}

Clinical Interventions in Aging is an international, peer-reviewed journal focusing on evidence-based reports on the value or lack thereof of treatments intended to prevent or delay the onset of maladaptive correlates of aging in human beings. This journal is indexed on PubMed Central, MedLine,

CAS, Scopus and the Elsevier Bibliographic databases. The manuscript management system is completely online and includes a very quick and fair peer-review system, which is all easy to use. Visit http://www.dovepress. $\mathrm{com} /$ testimonials.php to read real quotes from published authors.

Submit your manuscript here: http://www.dovepress.com/clinical-interventions-in-aging-journal 